\title{
TOCANTINS (IAC-23) E TUCURUÍ (IAC-24): NOVOS CULTIVARES DE TRIGO $\left({ }^{1}\right)$
}

\author{
JOÃO CARLOS FELÍCIO $(2,5)$, CARLOS EDUARDO DE OLIVEIRA CAMARGO $\left({ }^{2,5}\right)$, \\ ANTONIO WILSON PENTEADO FERREIRA FILHO $(2,5)$, \\ JOSÉ GUILHERME DE FREITAS $(2,5)$, BENEDITO DE CAMARGOBARROS $(3,5)$ \\ e POLICARPO VITTI $(4,5)$
}

\begin{abstract}
RESUMO
Os cultivares de trigo Tocantins (IAC-23) e Tucuruí (IAC-24), provenientes de cruzamentos artificiais e obtidos por seleção pelo método genealógico, foram avaliados quanto à produtividade de grăos e às reações aos agentes causais das ferrugens-do-colmo e da-folha na regiäo do Vale do Paranapanema, SP, em condição de sequeiro e, no caso do 'Tucuruî', com a utilização de irrigação por aspersão, na região Norte (SP). Esses cultivares foram avaliados também em relação às qualidades industriais de panificação. As produções médias de grãos de ambos não se apresentaram estatisticamente diferentes da produção da testemunha 'Anahuac', em condição de sequeiro. $O$ 'Tucurui' superou estatisticamente, em produção, o 'Anahuac' em solos com porcentagem de saturação por bases inferior a $60 \%$, com irri-
\end{abstract}

(1) Com verba suplementar do Acordo entre as Cooperativas de Produtores Rurais do Vale do Paranapanema e a Secretaria de Agricultura, por intermédio do Instituto Agronômico. Os autores agradecem à Dra. Elisa T. Coelho, do Centro Nacional de Pesquisa de Trigo, a colaboração na identificação das raças de ferrugem-do-colmo. Recebido para publicação em 25 de setembro e aceito em 30 de dezembro de 1987. (SP).

(2) Seção de Arroz e Cereais de Inverno, Instituto Agronômico (IAC), Caixa Postal 28, 13.001 Campinas nas (SP).

(3) Seção de Doenças das Plantas Alimentícias Básicas e Olerícolas, Instituto Biológico, 13.093 Campi-

(4) Seção de Cereais, Farinhas e Panificação, Instituto de Tecnologia de Alimentos (ITAL), 13.020 Campinas (SP).

$\left({ }^{5}\right)$ Com bolsa de pesquisa do CNPq. 
gaçāo, apresentando uma produtividade média de $2.842 \mathrm{~kg} / \mathrm{ha}$ contra $2.421 \mathrm{~kg} / \mathrm{ha}$. O 'Tucurur', de estatura semi-anã, apresentou-se tolerante à presença de $10 \mathrm{mg} /$ /itro de $\mathrm{Al}^{3+}$ e o 'Tocantins', de porte alto, exibiu sensibilidade à concentração de $6 \mathrm{mg} /$ litro de $\mathrm{A}^{3+}$, ambos em solução nutritiva. Os novos cultivares apresentaram moderada suscetibilidade à ferrugem-da-folha e baixos niveis de infecção para a ferrugern-do-colmo, bem próximos aos apresentados peio 'Anahuac'. Nos ensaios de panificação, a farinha do 'Tucurui', de maneira geral, propiciou pães de excelente qualidade física, com volume específico bastante superior à farinha de trigo comercial e levemente superior à do 'Tocantins'.

Termos de indexaçăo: cultura de trigo-de-sequeiro e imigada; produtividade; resistência às ferrugens; raças fisiológicas de ferrugens; características de panificaçāo.

\section{INTRODUÇÃO}

Os avanços conseguidos para elevar os rendimentos da cultura do trigo nos países em desenvolvimento, da Segunda Guerra Mundial até o presente, têm sido mais promissores do que os alcançados até então, desde a domesticação e o cultivo do cereal (HANSON et al., 1982). A planta tradicional de trigo era alta (125 a $150 \mathrm{~cm})$ e de palha fraca. Entretanto, um cultivar de trigo de origem japonesa, denominado Daruma, de baixa estatura (anão), tinha capacidade de transferir seu baixo porte aos descendentes de seus cruzamentos com outros trigos. Desses novos cruzamentos, resultou o 'Norim 10', que foi liberado para cultivo em 1935. Este cultivar tinha uma altura de 52 a $55 \mathrm{~cm}$, quando cultivado no Japão, e rendimentos excepcionalmente altos.

OSÓRIO (1982) cita que, de modo geral, os cultivares brasileiros de trigo têm porte alto, especialmente os cultivados ao sul do paralelo $24 \mathrm{~S}$. Os solos da região Sul do Brasil são, em geral, de baixa fertilidade, alcançando o trigo menor desenvolvimento, nāo ocorrendo normalmente acamamento, mesmo quando utilizados cultivares de alta estatura. Ao norte daquele paralelo, no trigo cultivado em solos de boa fertilidade, os cultivares altos sofrem intenso acamamento, sendo, portanto, indesejáveis.

Grandes áreas do território brasileiro têm solos ácidos, que contêm alumínio livre, que inibe o crescimento das raizes da maior parte dos cultivares de trigo, trazendo, como conseqüência, pouco perfilhamento e baixos rendimentos (HANSON et al., 1982).

BECKMAN (1954) destacou, entre centenas de cultivares estudados em solos ácidos, onde os cultivares de trigo apresentavam problemas de crescimento, 
um cultivar com nivel de tolerância para esse fator, Pollyssu, que foi selecionado em 1914 a partir do material original de trigo levado por imigrantes ao Rio Grande do Sul.

CARVALHO (1982) cita que a aplicação de corretivos, como calcário, para elevar o $\mathrm{pH}$ do solo e reduzir o efeito tóxico do Al e $\mathrm{Mn}$, resolve o problema apenas na camada arável, permanecendo inalteradas as partes inferiores do solo, o que fatalmente acarreta uma diminuição no comprimento das raízes das plantas sensiveis a esses elementos.

CAMARGO (1984), estudando a herdabilidade para oito caracteres agronômicos de trigo e a associação deles com a tolerância ao $\mathrm{Al}^{3+}$ e a produção de grãos, observou que a tolerância ao alumínio não esteve associada com a altura das plantas (com exceção da correlação fenotipica no cruzamento Alondra-S-46/IAC-5). Concluiu o autor ser possivel selecionar, nas populações segregantes, plantas tolerantes ao alumínio, de porte médio, com maior fertilidade da espiga, alto potencial de produtividade e adaptação à maioria dos solos ácidos das regiões tritícolas brasileiras.

O instituto Agronômico, mediante trabalhos de melhoramento genético, vem selecionando novos cultivares de trigo (FELICIO et al., 1983, 1985), mais adaptados às condições de sequeiro paulista, entre eles: IAC-17 (Maracaí), IAC-18 (Xavantes), IAC-21 (Iguaçu) e IAC-22 (Araguaia), todos considerados como de porte alto e tolerantes ao $\mathrm{Al}^{3+}$.

O presente trabalho teve por objetivo estudar o comportamento de dois novos cultivares de trigo, Tocantins (IAC-23) e Tucuruí (IAC-24), em culturas de sequeiro e com irrigação, no Estado de São Paulo, ao norte do paralelo $24 \mathrm{~S}$.

\section{MATERIAL E MÉTODOS}

O cultivar Tocantins (IAC-23), obtido pelo método genealógico (ALLARD, 1960), originou-se do cruzamento PEL A 393.65/LAC-5. O 'PEL A 393.65' foi introduzido do Instituto de Pesquisa Agropecuária do Sul (IPEAS), Pelotas (RS). O 'IAC-5' (Maringá), oriundo da progênie 16.494, proveio do híbrido entre a progênie 7124 e a variedade Polyssu (PG 1), em 1956, na Estação Experimental de Capão Bonito, do Instituto Agronômico. O 7124 resultou do cruzamento 'Frontana'/'Kenya 58', feito em 1951 (CAMARGO, 1972). O 'Tocantins' apresenta as seguintes caracteristicas agronômicas: altura entre 100 e $115 \mathrm{~cm}$, ciclo precoce, 120 dias, da maturação à colheita, aurícula verde-clara, posição das folhas intermediária, panícula creme, aristada, fusiforme, com grāos de cor creme com comprimento de $6,38 \mathrm{~mm}$, largura de $3,13 \mathrm{~mm}$ e espessura de $2,44 \mathrm{~mm}$, em média ( $\mathrm{Fi}$ gura (A). 

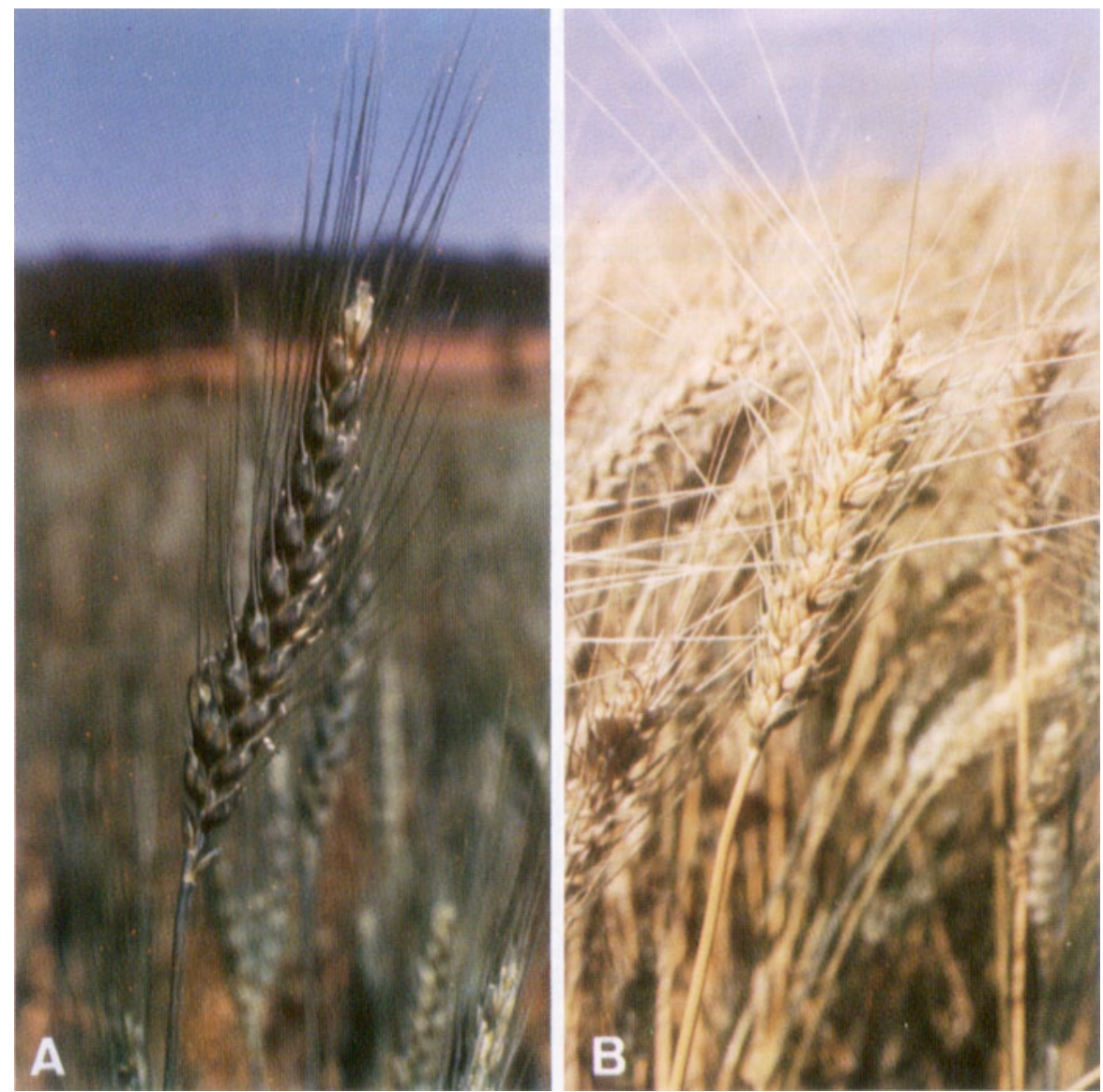

FIGURA 1. A: Espiga característica do cultivar Tocantins (IAC-23) na época de florescimento. B: Espiga característica do cultivar Tucurui (IAC-24) na épóca de maturação.

O cultivar Tucuruí (IAC-24), também obtido pelo métödo genealógico, originou-se do cruzamento 'IAS 51'/IRN 597-70. O 'IAC 51' (Albatroz), de genealogia desconhecida, foi introduzido do IPEAS, Petotas (RS). O tRN 597-70 = (SON $64 / Y 50$ E//GTO/3/2* CNO 67) foi introduzido através do International Spring Wheat Rust Nursery de 1970, proveniente dos EUA, mas originário do México. O 'Tucurui' apresenta as seguintes caracteristicas agronômicas: altura média de $80 \mathrm{~cm}$, ciclo precoce, 120 dias, da maturação à colheita; aurícula violácea, não em toda a área; posição das folhas intermediária; coloração da panícula creme, aristada, oblonga, grãos-avermelhados com comprimento de $5,91 \mathrm{~mm}$, largura de $3,05 \mathrm{~mm}$ e espessura de $2,47 \mathrm{~mm}$, em média (Figura 1B). 
Instalaram-se no periodo $1980-1985$, na região tritícola paulista do Vale do Paranapanema (Sudoeste do Estado), em condições de sequeiro, dezesseis experimentos, nas seguintes localidades: Maracai e São José das Laranjeiras, em 1980; Palmital e Maracaí, em 1981; Palmital, Maracaí e São José das Laranjeiras, em 1982, 1983 e 1984, e em Palmital, Maracaí, São José das Laranjeiras e Cruzália, em 1985. Os experimentos foram compostos pelos cultivares Tocantins e Tucuruí, além da testemunha, 'Anahuac', originário do México, com alta suscetibilidade ao alumínio tóxico (CAMARGO \& FELICIO, 1986). Empregou-se o delineamento de blocos casualizados com quatro repetiçōes por local, constituindo-se cada parcela de cinco linhas de $5 \mathrm{~m}$ de comprimento, espaçadas de $0,20 \mathrm{~m}$, com uma separação lateral, entre as parcelas, de $0,60 \mathrm{~m}$. Procedeu-se à semeadura, com oitenta sementes viáveis por metro de sulco, sendo efetuada a colheita da área total das parcelas, ou seja, $5 \mathrm{~m}^{2}$. Nas áreas de irrigação por aspersão semearam-se dez experimentos na região Norte do Estado de São Paulo, nas seguintes localidades: Guaira e Colômbia, em 1983; Campinas, Aguaí, Colômbia e Guaíra, em 1984 e 1985. Adotou-se delineamento semelhante ao usado nos ensaios de sequeiro, para a comparação da produção média de grãos entre os cultivares Tucurui e Anahuac. Nas comparaçōes das médias das produçōes de grãos transformadas em quilograma por hectare, empregou-se o teste de Duncan a $5 \%$ (PIMENTEL GOMES, 1963).

Todos os experimentos receberam adubação a lanço, constante de $20 \mathrm{~kg}$ de $\mathrm{N}, 60 \mathrm{~kg}$ de $\mathrm{P}_{2} \mathrm{O}_{5}$ e $20 \mathrm{~kg}$ de $\mathrm{K}_{2} \mathrm{O}$, por hectare, nas formas de sulfato de amônio, superfosfato simples e cloreto de potássio respectivamente.

Anteriormente à instalação de cada experimento, retiraram-se amostras compostas dos solos cujas análises foram efetuadas pela Seção de Fertilidade do Solo e Nutrição de Plantas do Instituto Agronômico.

Para o estudo do comportamento dos cultivares em relação à terrugem-do-colmo (Puccinia graminis f. sp. tritici) e ferrugem-da-folha (Puccinia recondita f. sp. tritici), efetuaram-se avaliações em plântulas no Centro Nacional de Pesquisa de Trigo, de acordo com critérios apresentados no quadro 4 e em plantas adultas em condições de campo (Vale do Paranapanema), usando-se a escala modificada de Cobb, adotada no International Rust Nursery e utilizada por SCHRAM ef al. (1974), a qual é composta por um número estimativo de ataque da moléstia no colmo e na folha, acrescido de letra simbolizando o tipo de reação: $S=$ suscetivel; $M S=$ moderadamente suscetivel; $M=$ intermediário; $M R$ $=$ moderadamente resistente $R=$ resistente (Quadros 5 e 6 ).

Na mediçāo da altura da planta de cada cultivar, levou-se em consideração a distância do nível do solo ao ápice da espiga, mantendo-se as plantas esticadas, excluindo-se as aristas. 
Para a determinação da tolerância ao $\mathrm{Al}^{3+}$, empregou-se a técnica descrita por CAMARGO \& OLIVEIRA (1981), que consiste no teste em soluçāo nutritiva contendo, respectivamente, $0,2,4,6,8$ e 10mg por litro de alumínio na forma de $\mathrm{Al}_{2}\left(\mathrm{SO}_{4}\right)_{3} 18 \mathrm{H}_{2} \mathrm{O}$. Foram utilizados como controle os cultivares $\mathrm{BH}-1146$ (tolerante) e Anahuac (sensivel).

Para a irrigação, adotou-se a metodologia proposta por SILVA et al. (1984): consiste em uma irrigação inicial após a semeadura de 40 a $50 \mathrm{~mm}$, com a finalidade de umedecer o perfil do solo, e a instalação de tensiômetros em pontos diferentes a uma profundidade de $12 \mathrm{~cm}$. Efetuaram-se as irrigaçōes complementares quando a média das leituras dos tensiômetros apresentava 0,6 atm, e a lâmina líquida aplicada for determinada através da evaporaçāo acumulada medida no tanque classe $A$, nos intervalos das irrigaçōes.

Os grãos de trigo dos cultivares IAC-23 e IAC-24 foram submetidos inicialmente a testes de moagem, para determinação das caracteristicas de rendimento. Utilizou-se, para tal, o moinho piloto Bühler, modelo MLU-202, trabaihando-se com $5 \mathrm{~kg}$ de grãos para cada ensaio de moagem.

Os grãos tiveram sua umidade acertada de acordo com a metodologia oficial (ARBEITSGEMEINSCHALT, 1971). Na moagem, determinou-se o rendimento em farinha, farelo grosso e farelo fino.

As farinhas obtidas da moagem foram submetidas a análises de ordem física no farinógrafo, amilógrafo e extensógrafo, segundo métodos da AACC (1969). O teor e a qualidade do glúten e o "falling number" foram determinados segundo BAR (1982) e o expansograma, de acordo com o método oficial (ARBEITSGEMEINSCHALT, 1971).

Para os testes de panificação, utilizou-se a formulação descrita por VITTI et al. (1982). Preparou-se o pāo do tipo de 80 gramas de massa por unidade e compararam-se os pães com aqueles preparados com farinha de trigo comercial.

O preparo dos pães tipo francês seguiu metodologia descrita por VITTI et al. (1980), e sua avaliação foi efetuada de acordo com VITTI et al. (1982).

\section{RESULTADOS E DISCUSSÃO}

As médias de produção de grãos obtidas nos experimentos conduzidos no período 1980-1985, na região do Vale do Paranapanema, em condições de sequeiro, encontram-se no quadro 1. A análise estatística dos dados revelou que não houve efeitos significativos para cultivares e interação cultivares $x$ anos, ocorrendo, entretanto, um efeito altamente significativo de anos, sendo o de 1985 o melhor quanto à produtividade. Nesse ano, ocorreram chuvas em quantidade superior à'média da regiâo e muito bem distribuídas durante o ciclo da cultura, favorecendo o aumento da produtividade dos cultivares de trigo. 
QUADRO 1. Produçōes médias de grãos obtidas nos ensaios de cultivares de trigo conduzidos em condiçōes de sequeiro na região do Vale do Paranapanema (SP) em 1980-1985

\begin{tabular}{|c|c|c|c|c|c|c|c|}
\hline Cultivares & 1980 & 1981 & 1982 & 1983 & 1984 & 1985 & Média \\
\hline & & & & - $\mathrm{kg} / \mathrm{ha}$ & & & \\
\hline IAC-24 & $1555 a$ & $873 c$ & $898 b$ & $882 a$ & $1139 a$ & $1856 a$ & $1200 a\left({ }^{1}\right)$ \\
\hline IAC-23 & $1367 a$ & $1066 b$ & $1433 a$ & $901 a$ & $921 \mathrm{a}$ & $1648 a$ & $1223 a$ \\
\hline Anahuac & $1459 a$ & $1199 a$ & $993 b$ & $1025 a$ & $889 a$ & $1690 \mathrm{a}$ & $1209 a$ \\
\hline Média( $\left.{ }^{2}\right)$ & $1460 \mathrm{~b}$ & $1046 \mathrm{~cd}$ & $1108 c$ & $936 d$ & $983 c d$ & $1731 a$ & \\
\hline F (Cultivares) & 0,09 & $140,00^{* *}$ & $39,50^{* *}$ & 0,58 & 3,29 & 1,56 & 0,15 \\
\hline$F(A n o s)$ & & & & & & & $3,12^{\star \star}$ \\
\hline$F$ (Cultivares $x$ anos) & & & & & & & 0,71 \\
\hline
\end{tabular}

(1) Médias para a comparação da produção de grãos entre cultivares dentro de cada ano e entre a produção de grāos dos cultivares dentro dos anos seguidas pelas mesmas letras no sentido vertical não diferem estatisticamente pelo teste de Duncan ao nível de $5 \% .\left({ }^{2}\right)$ Médias para a comparação da produção de grāos entre anos seguidas pelas mesmas letras no sentido horizontal não diferem estatisticamente pelo teste de Duncan ao nivel de $5 \%$.

** Significativo ao nivel de $1 \%$.

Verificaram-se somente diferenças significativas entre os cultivares nos anos de 1981 e 1982, que podem ser considerados climaticamente atípicos. Ocorreram baixas temperaturas e má distribuição de chuvas em 1981 e precipitações pluviais excessivas no final do ciclo vegetativo do trigo em 1982, favorecendo a ocorrência de doenças nas espigas. Nessas condições, destacaram-se, pela produção de grãos, o cultivar Anahuac em 1981 e IAC-23 em 1982. Na média dos dezesses experimentos, não se detectaram diferenças quanto à produção de grãos entre os três cultivares.

O quadro 2 apresenta as produções de grãos para os ensaios conduzidos com irrigação no Estado de São Paulo. A análise estatística dos dados obtidos no conjunto de todos os ensaios não mostrou diferenças significativas entre a produção de grãos dos cultivares Anahuac e IAC-24. O mesmo resultado foi obtido nos ensaios cujas glebas apresentaram porcentagem de saturação por bases superior a 60 (baixa acidez). Entretanto, quando foram considerados os experimentos em solos com V\% inferior a 60 (alta acidez), detectaram-se diferenças entre os cultivares. Foram determinados efeitos altamente significativos para anos e não-significativos para cultivares $x$ anos nos experimentos conduzidos em solos com baixa ou com elevada acidez. 
QUADRO 2. Produçōes médias de grãos obtidas nos ensaios de cultivares de trigo conduzidos em condiçōes de irrigação por aspersāo no Estado de São Paulo em 1983-1985 em solos considerados de baixa e de alta acidez

\begin{tabular}{|c|c|c|c|c|c|c|c|c|}
\hline \multirow{2}{*}{ Cultivares } & \multicolumn{2}{|c|}{1983} & \multicolumn{2}{|c|}{1984} & \multicolumn{2}{|c|}{1985} & \multicolumn{2}{|c|}{ Média Geral } \\
\hline & BA & AA & BA & AA & $\mathrm{BA}$ & $A A$ & $\mathrm{BA}$ & $A A$ \\
\hline & & & 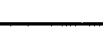 & - $\mathrm{kg}$ & ha & & & \\
\hline Anahuac & $2212 a$ & $1976 a$ & $2801 a$ & $2279 a$ & $3210 a$ & $3008 a$ & $2471 a\left({ }^{1}\right)$ & $2421 b$ \\
\hline IAC-24 & $2149 a$ & $2278 a$ & $2391 \mathrm{a}$ & $2745 a$ & $3226 a$ & $3502 a$ & $2589 a$ & $2842 a$ \\
\hline Média $\left.{ }^{2}\right)$ & $2180 \mathrm{c}$ & $2127 c$ & $2596 b$ & $2512 b$ & $3218 a$ & $3255 a$ & & \\
\hline $\mathrm{F}$ (Cultivares) & 0,18 & 1,63 & 3,89 & 3,87 & 0,02 & 4,18 & 1,36 & $49,35^{\star \star}$ \\
\hline$F(A n o s)$ & & & & & & & $21,24^{\star \star}$ & $61,12^{\star *}$ \\
\hline$F$ (Cultivares $x$ anos) & & & & & & & 0,593 & 0,267 \\
\hline
\end{tabular}

(1) Médias para a comparação da produçāo de grăos entre cultivares dentro de cada ano e entre a produçao de gräos dos cultivares dentro dos anos seguidas pelas mesmas letras no sentido vertical não diferem estatisticamente pelo teste de Duncan ao nível de $5 \%$. $\left({ }^{2}\right)$ Médias para a comparaçāo da produçāo de gräos entre anos, em condiçōes de solo de baixa e de alta acidez, seguidas pelas mesmas letras no sen. tido horizontal năo diferem estatisticamente pelo teste de Duncan ao nivel de $5 \%$.

** Significativo ao nivel de $1 \%$.

BA. Solos de baixa acidez $V \%>60$. AA Solos de alta acidez $V \%<60$.

Independente dos cultivares e dos níveis de acidez do solo, as maiores produções de grãos de trigo ocorreram em 1985, que apresentou condiçōes climáticas favoráveis à cultura e pequena ocorrência de doenças.

Nos solos com elevada acidez, o cultivar IAC-24, na média dos experimentos estudados com irrigação, superou o 'Anahuac' em $421 \mathrm{~kg} / \mathrm{ha}(17,4 \%)$ com respeito à produção de grãos, mostrando boa adaptação a essas condições. $O$ 'IAC-24', em solos com baixa acidez, mostrou produções de grãos não diferentes estatisticamente das encontradas para o 'Anahuac'. Estes resultados discordam dos obtidos por PRIOLI (1987), que mostrou em milho uma associação entre baixa produtividade e tolerância ao $\mathrm{Al}^{3+}$ quando os hibridos foram cultivados em solos de baixa acidez.

A toxicidade devida ao aluminio tem limitado a produção de trigo em muitas terras agricultáveis, além de impedir a expansão da área mundialmente cultivada com esse cereal. No quadro 3 , encontram-se os resultados das avaliações dos cultivares de trigo quanto à tolerância ao $\mathrm{Al}^{3+}$ feitas em soluções nutritivas contendo seis diferentes concentrações de aluminio. $O$ 'Anahuac' apresentou alta suscetibilidade ao $\mathrm{Al}^{3+}$; o 'IAC-23', plantas sensiveis na concentração de 6 $\mathrm{mg} /$ litro e, os cultivares $\mathrm{BH}-1146$ e $\mid \mathrm{AC}-24$, tolerância na concentração de 10 
mg/ilitro. De acordo com CAMARGO (1984), é possível selecionar plantas que combinem tolerância ao $\mathrm{Al}$, porte semi-anão e alto potencial produtivo, como ocorreu com o cultivar 'Tucuruí'. O 'Anahuac', que também apresenta porte semianão, não conseguiu mostrar seu potencial produtivo em solos ácidos, devido a sua alta sensibilidade ao alumínio.

QUADRO 3. Comprimento médio das raízes de cultivares de trigo medido após 72 horas de crescimento nas soluções nutritivas completas que se seguiu a crescimento durante 48 horas nas soluçōes tratamentos contendo seis diferentes concentrações de alumínio

\begin{tabular}{|c|c|c|c|c|c|c|c|}
\hline \multirow{2}{*}{ Cultivares } & \multicolumn{7}{|c|}{ Concentração de $\mathrm{Al}^{3+}$ nas soluçōes tratamentos (mg/litro) } \\
\hline & 0 & 2 & 4 & 6 & 8 & 10 & \\
\hline Anahuac & 62,3 & 0,0 & 0,0 & 0,0 & 0,0 & 0,0 & AS \\
\hline $\mathrm{BH} 1146$ & 95,1 & 62,6 & 48,0 & 40,3 & 32,6 & 26,6 & $T$ \\
\hline $\mathrm{IAC}-23$ & 56,9 & 26,6 & 12,8 & 0,0 & 0,0 & 0,0 & $S$ \\
\hline IAC-24 & 50,8 & 34,4 & 34,5 & 29,2 & 14,1 & 3,7 & $T$ \\
\hline
\end{tabular}

$T$ : apresenta crescimento das raizes em $10 \mathrm{mg} / \mathrm{l}$ do $\mathrm{Al}^{3+}$. S: apresenta crescimento das raizes em $2 \mathrm{mg} / \mathrm{l}$ do $A l^{3+}$, mas é sensivel a $6 \mathrm{mg} / \mathrm{l}$ de $\mathrm{Al}^{3+}$. AS: é sensivel a $2 \mathrm{mg} / \mathrm{l}$ de $\mathrm{Al}{ }^{3+}$

Com relação à resistência dos novos cultivares à ferrugem-do-colmo (Puccinia graminis f. sp. tritici), em casa de vegetação, conforme se pode verificar no quadro 4, o cultivar IAC-23 apresentou resistência a treze raças entre as catorze utilizadas no teste, porém mostrou-se moderadamente suscetivel à raça G19. O 'IAC-24' apresentou resistência a onze raças, moderada suscetibilidade à G17 e suscetibilidade às raças G18 e G20 (COELHO, 1986).

QUADRO 4. Reações de cultivares de trigo às raças de Puccinia graminis f.sp. tritici, em casa de vegetação, no estádio de plântula

Cultivares

Raças de Puccinia graminis tritici

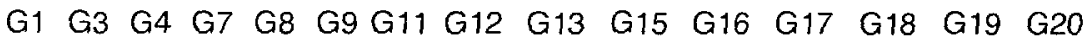

\begin{tabular}{|c|c|c|c|c|c|c|c|c|c|c|c|c|c|c|}
\hline Anahuac & 0 & 0 & 0 & 0 & 0 & $2+$ & 1 & 2 & 4 & $1-$ & & 0 & 0 & 2 \\
\hline $\mathrm{BH} 1146$ & 2 & $3-$ & 4 & 4 & $2+$ & 4 & 4 & 4 & 4 & 4 & $2++$ & 4 & 4 & 3 \\
\hline $\mid A C-23$ & 0 & 0 & 0 & 0 & & 1 & 0 ; & 2 & 0 & $1-$ & 1 & $1-$ & 1 & 3 \\
\hline $\mid A C-24$ & 0 & 0 & 0 & 0 & 0 & 0 & & 1 & 0 & $1+$ & 0 & 3 & 4 & 2 \\
\hline
\end{tabular}

Escala de leitura adotada: 0 imune; $0 ; 1$ e 2 resistente; $2+$ e $2++$ moderadamente resistente; $3-$ e $3--$ moderadamente suscetivel; 3 e 4 suscetfvel. 
Em condições de campo, no Vale do Paranapanema, os novos cultjvares apresentaram graus de infecção para ferrugem-da-folha superiores aos apresentados pela testemunha 'Anahuac' (Quadro 5). Os cultivares IAC-23 e IAC-24 podem ser considerados como de moderada suscetibilidade a essa ferrugem, pois exibiram, em média, graus $20 \mathrm{~S}$ e $22 \mathrm{~S}$ respectivamente, quando se sabe que cultivares de alta suscetibilidade apresentam graus superiores a $80 \mathrm{~S}$ (porcentagem da área foliar infectada pelo patógeno).

QUADRO 5. Reações médias e média geral de cultivares de trigo em relação à ferrugemda-folha no periodo de 1980-85, no Vale do Paranapanema (SP)

\begin{tabular}{lrrrrrrr}
\hline Cultivares & 1980 & 1981 & 1982 & 1983 & 1984 & 1985 & Média \\
\hline IAC-23 & $25 S$ & $20 S$ & $25 S$ & $10 S$ & $20 S$ & $20 S$ & $20 S$ \\
IAC-24 & $25 S$ & $20 S$ & $20 S$ & $20 S$ & $20 S$ & $25 S$ & $22 S$ \\
Anahuac & $10 S$ & $5 S$ & $10 S$ & $20 S$ & $10 S$ & $5 S$ & $10 S$ \\
\hline
\end{tabular}

S: suscetivel.

Para a ferrugem-do-colmo - Quadro 6 - pode-se considerar que os niveis de infecção dos novos cultivares estiveram bem próximos da testemunha, demonstrando suscetibilidade semelhante. Em 1984 e 1985, a ocorrência dessa moléstia foi insignificante, não chegando a manifestar reaçōes nos cultivares em estudo.

QUADRO 6. Reaçōes médias e média geral de cultivares de trigo em relação à ferrugemdo-colmo no período de 1980-85, no Vale do Paranapanema (SP)

\begin{tabular}{lccccc}
\hline Cultivares & 1980 & 1981 & 1982 & 1983 & Média \\
\hline IAC-23 & $5 S$ & $5 S$ & $10 M S$ & $20 S$ & $10,0 S$ \\
IAC-24 & $5 S$ & tR & $10 S$ & $25 S$ & $10,0 S$ \\
Anahuac & $10 S$ & tS & $5 M S$ & $20 S$ & $8,7 S$ \\
\hline
\end{tabular}

S: suscetivel; MS: moderadamente suscetivel; MR: moderadamente resistente; tS: plantas com poucas pústulas com reação de suscetibilidade; tR: plantas com poucas pústulas com reação de resistência.

Obs: Não houve ocorrência da moléstia em 1984 e 1985.

Os resultados do teste de moagem dos trigos IAC-23 e IAC-24 no moinho Bühler acham-se no quadro 7 . O rendimento do IAC-23 pode ser considerado relativamente bom, principalmente se comparado a variedades de trigo americano 
ou canadense, que chegam a dar valores de até $70 \%$ de rendimento. Deve-se salientar, entretanto, que, geralmente, no moinho Bühler piloto, os valores de rendimento em moagem são sempre menores nos cultivares de trigo nacional, que, por via de regra, devido às suas próprias características intrínsecas, apresentam dificuldades de moagem. Chamou a atenção neste aspecto o comportamento em rendimento do 'IAC-24', que superou mesmo as variedades norte-americanas. Em relação a esse cultivar, deve-se salientar o aspecto da presença de uma coloração levemente escura da farinha, talvez devido à própria coloração mais escura do grão que, durante o processo de moagem, acaba passando para a farinha. Com relaçāo às características do glúten, o 'IAC-23' apresentou porcentagem superior ao 'IAC-24', porém de qualidade inferior. Isso pode refletir na resistência da massa, durante o processo de panificação e nas características de retenção de gás carbônico produzido na fermentação. $O$ "falling number", que se relaciona com a atividade enzimática da farinha, mostrou valor melhor para o IAC-24, isto é, mais indicativo de tendência a propiciar miolo menos seco e levemente úmido, o que, do ponto de vista da panificação, é interessante. Quanto mais próximo esse valor estiver de 300 segundos, mais equilibrada é a farinha em termos de atividade enzimática. Na verdade, ocorre que, à medida que aumenta a atividade enzimática (valores muito baixos em segundos), há maior ação das enzimas aminolíticas sobre o amido, desdobrando-o. Como resultado dessa ação das enzimas, há uma sobra de água, que usualmente é absorvida pelo amido para gelatinizar, caso não tivesse sido transformado. Aparecendo em excesso, esse amido irá propiciar pão de miolo mais úmido e pegajoso. O 'IAC-24' exibiu "falling number" de 449 segundos, indicando maior atividade enzimática do que o 'IAC-23' e, portanto, tendência a produzir pão levemente mais úmido.

O teste de amilógrafo - Quadro 8 - indicou a mesma tendência do "falling number", isto é, menor viscosidade, atividade enzimática maior e mais próxima dos valores ideais (700-1.000 unidades). Valores acima de 1.500 unidades indicam a tendência de obter-se pão de miolo muito seco, e valores abaixo de 700 indicam miolo muito úmido.

QUADRO 7. Características físicas da farinha de trigo dos cultivares IAC-23 e IAC-24

\begin{tabular}{lcccc}
\hline Amostras & R.M. & T.G.U. & Q.G. & F.N. \\
\hline & $\%$ & $\%$ & $\mathrm{~cm}^{3}$ & seg \\
IAC-23 & 63,0 & 35 & 8 & 501 \\
IAC-24 & 71,9 & 27 & 26 & 449 \\
\hline
\end{tabular}

RM: rendimento em moagem; T.G.U.: teor de glúten úmido; Q.G.: qualidade de glúten; F.N.: "falling number". 
QUADRO 8. Características farinográficas e amilográficas da farinha de trigo dos cultivares IAC-23 e IAC-24

\begin{tabular}{|c|c|c|c|c|c|c|c|c|}
\hline \multirow{2}{*}{ Amostras } & \multicolumn{5}{|c|}{ Extensógrafo } & \multicolumn{3}{|c|}{ Expansógrafo } \\
\hline & T.D. & R. & E. & A. & Ab. & T.G. & V.M. & T.V.M. \\
\hline & $\min$ & $\min$ & $\min$ & U.F. & $\%$ & ${ }^{\circ} \mathrm{C}$ & U.A. & ${ }^{\circ} \mathrm{C}$ \\
\hline IAC-23 & $3: 00$ & $4: 30$ & $1: 30$ & 60 & 56,0 & 61,5 & 1840 & 90 \\
\hline IAC-24 & $6: 00$ & $9: 00$ & $3: 00$ & 40 & 56,5 & 57,0 & 1560 & 88 \\
\hline
\end{tabular}

T.D.: tempo de desenvolvimento; R: resistência $=E+T$.D.; E: estabilidade; $A$ : abrandamento em unidade farinográfica U.F. Brabender; Ab: absorção; T.G.: temperatura de gelatinização; V.M.: viscosidade máxima a quente em unidades amilográficas Brabender; T.V.M.: temperatura de viscosidade máxima.

Pelos resultados obtidos nos testes de farinógrafo, os valores para o 'IAC-24' mostraram-se superiores, principalmente em relação ao valor de resistência $(R)$. Isto significa que a massa pode ser trabalhada durante um período de tempo mais longo, sem apresentar alteraçāo nas suas caracteristicas reológicas relativas ao glúten. Uma caracteristica notada no 'IAC-24' é quanto ao tempo de desenvolvimento da massa (T.D.), que foi de seis minutos, indicando absorção de água mais lenta para atingir a unidade farinográfica \pm 500 , que orienta o teste. Valores altos de resistência significam melhor comportamento da massa durante a fase de mistura, isto é, há um desenvolvimento correto do glúten e, conseqüentemente, maiores possibilidades de obter pão de melhor qualidade.

Pelo quadro 9 , pode-se também observar as características físicas das massas preparadas com a farinha de trigo dos dois cultivares. No expansógrafo, - 'IAC-24' propiciou obtenção de massa com melhores caracteristicas de retenção de $\mathrm{CO}_{2}$. Apesar de o 'IAC-23' ter apresentado capacidade de produção de $\mathrm{CO}_{2}$ levemente superior, o mais importante é a retenção do gás medido pela estabilidade da massa, que foi superior no 'IAC-24'. Isso significa que a perda de $\mathrm{CO}_{2}$ pela diminuição da resistência da película formada pelo glúten foi menor no 'IAC-24'. Em termos de panificação, è de esperar um produto de melhor qualidade utilizando o 'IAC-24'. Durante o processo de panificação, a perda de $\mathrm{CO}_{2}$ pela massa foi maior no caso do 'IAC-23' e, conseqüentemente, com maiores possibilidades de produzir pães de menor volume, o que é indesejável. Com relação à extensibilidade da massa após 135 minutos de descanso, o 'IAC-23' apresentou extensibilidade um pouco maior. Entretanto, o 'IAC-24' mostrou resistência à deformação melhor do que o primeiro, indicando ter reação mais favorável à adição de melhoradores do tipo oxidante (BLOKSMA, 1964). 
QUADRO 9. Características expansográficas e extensográficas da farinha de trigo dos cultivares IAC-23 e IAC-24

\begin{tabular}{|c|c|c|c|c|c|c|}
\hline \multirow{2}{*}{ Amostra } & \multicolumn{4}{|c|}{ Extensógrafo } & \multicolumn{2}{|c|}{ Expansógrafo } \\
\hline & R. & E. & $\mathrm{Rz}$. & A. & C.P. & Es. \\
\hline & U.E. & $\mathrm{mm}$ & & $\mathrm{cm}^{2}$ & $\mathrm{~mm}$ & $\mathrm{~mm}$ \\
\hline IAC-23 & 150 & 232 & 0,65 & 81,2 & 68,5 & 44,5 \\
\hline $\mid A C-24$ & 250 & 181 & 1,32 & 90,9 & 65,0 & 86,0 \\
\hline
\end{tabular}

R: resistência em unidades extensográficas Brabender, E.: extensibilidade; Rz.: razão; A.: área; C.P.: capacidade de produçāo de $\mathrm{CO}_{2}$.

Nenhum dos métodos reológicos ou químicos empregados isoladamente é capaz de prever exatamente as características finais do pão. Esses ensaios de laboratório são indicadores de tendências. Dessa forma, o teste de panificação - Quadro 10 - dá uma visão real do comportamento da farinha. No presente trabaIho, as tendências foram confirmadas por esses testes. Os valores de volume específico dos pães, empregando-se farinhas dos cultivares IAC-24 e IAC-23, mostraram o bom comportamento delas em relação à farinha comercial. $O$ 'IAC-24' confirmou as tendências dos testes reológicos, propiciando pães de excelente qualidade física, com o volume específico bastante superior à referência, e levemente superior ao 'IAC-23'. Com relação às características internas e externas do pão, dadas pelo C.T.C., pouca diferença se observou entre as amostras.

QUADRO 10. Características dos pães obtidos com farinha de trigo dos cultivares IAC-23 e IAC-24

\begin{tabular}{|c|c|c|}
\hline Amostra & V.E.C. & C.T.C. \\
\hline & $\%$ & $\%$ \\
\hline IAC-23 $\ldots \ldots \ldots \ldots \ldots$ & 112,6 & 101 \\
\hline 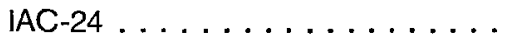 & 121,0 & 102 \\
\hline
\end{tabular}

V.E.C.: volume especifico comparativo à farinha de trigo comercial (V.F. $=100 \%$ ); C.T.C.: contagem total comparativa à farinha de trigo comercial (C.T.C. $=100 \%$ ).

\section{CONCLUSÕES}

1) Os cultivares de trigo IAC-23 e IAC-24 não apresentaram diferença na produtividade de grãos em comparação ao 'Anahuac' em condições de sequeiro, na região do Vale do Paranapanema (SP). Em condiçōes irrigadas, no Norte do Estado de São Paulo e em solo de alta acidez (V\% <60), o cultivar IAC-24 foi superior em produtividade à testemunha 'Anahuac'. 
2) O 'IAC-24' apresentou-se tolerante; o IAC-23, moderadamente tolerante e o 'Anahuac', sensivel à toxicidade de $\mathrm{Al}^{3+}$.

3) Os cultivares IAC-23 e IAC-24 apresentaram suscetibilidade ao agente causal da ferrugem-da-folha, em condições de campo, superiores à ocorrida no 'Anahuac'. Para a ferrugem-do-colmo, as reações ao agente causal não foram diferentes à verificada para a testemunha.

4) O 'IAC-24', em relação ao 'IAC-23', apresentou melhor comportamento nos testes reológicos, químicos e de panificação. Neste último, o seu volume específico foi superior ao obtido na farinha comercial (referência) e levemente superior ao 'IAC-23'.

\section{SUMMARY}

\section{TOCANTINS (IAC-23) AND TUCURUI (IAC-24):} NEW WHEAT CULTIVARS

The wheat cultivars Tocantins (IAC-23) and Tucurui (IAC-24) were obtained by hybridization and screened by the pedigree method from the segregating generations. These genotypes were evaluated for grain yield and resistance to stem and leaf rusts in several experiments carried out in different locations, with and without irrigation, in the State of São Paulo, Brazil, in the period 1980-85. They were also evaluated in relation to industrial qualities for bread production. In upland condition, the cultivars Tocantins and Tucurui did not differ in grain yield from the control cultivar Anahuac. 'Tucurui' differed from 'Anahuac' in the irrigated experiments carried out in acid soils. Under these conditions Tucurui cultivar produced 2,842 and the Anahuac $2,421 \mathrm{~kg} / \mathrm{ha}$. 'Tucurui', a semidwarf type, showed tolerance to $10 \mathrm{mg} / \mathrm{l}$ of Al in nutrient solution. 'Tocantins' presented susceptibility to $6 \mathrm{mg} /$, in the same conditions. The new cultivars were moderately susceptible to leaf rust infection and showed low levels of stem rust infection like the cultivar Anahuac. 'Tucurui' exhibited better bread qualities than the used commercial wheat flour and presented a little superior performance when compared with 'Tocantins'.

Index terms: upland and irrigated conditions; grain yield, rust resistance, physiological rust races, bread qualities.

\section{REFERÊNCIAS BIBLIOGRÁFICAS}

ALLARD, R.W. Principles of plant breeding. New York, John Wiley \& Sons, 1960. 381 p. AMERICAN ASSOCIATION OF CEREAL CHEMISTS. Methods of analysis of AACC. St. Paul, Minn., 1969.

ARBEITSGEMEINSCHALT fuer Getreidefosghung Standart fuer Getreideund, Brot. Detmold, Ed. Moritz Schaefer, 1971. $138 \mathrm{p}$. 
BAR, W.H. Análise e avaliação do trigo e dos produtos derivados. Campinas, ITAL, 1982. $154 p$.

BECKMAN, 1. Sobre o cultivo e melhoramento do trigo (Triticum vulgare Vill) no Sul do Brasil. Agronomia Sulriograndense, Porto Alegre, 1:64-72, 1954.

BLOKSMA, A.H. Rheology and chemistry of dough. In: POMERAMZ, Y., ed. Wheat: chemistry and technology. St. Paul, Minn., AACC, 1964. 821p.

CAMARGO, C.E.O. Estudos de variedades de trigo para o Estado de São Paulo. Piracicaba, E.S.A. "Luiz de Qúeiroz", 1972. 102p. Tese (Doutoramento)

-... Melhoramento do trigo. Estimativas da herdabilidade e correlações entre tolerância à toxicidade de aluminio e produçăo de grãos com outros caracteres agronômicos em trigo. Bragantia, Campinas, 43(2):615-628, 1984.

— \& FELÍCIO, J.C. Melhoramento genético do trigo, no Instituto Agronômico. $O$ Agronômico, Campinas, 38(3):213-228, 1986.

\& OLIVEIRA, O.F. Tolerância de cultivares de trigo a diferentes níveis de aluminio em solução nutritiva e no solo. Bragantia, Campinas, 40:21-31, 1981.

CARVALHO, F.I.F. Genética quantitativa. In: FUNDAÇĀO CARGILL. Trigo no Brasil. Campinas, 1982. v.1,p.65-92.

COELHO, E.T. Ferrugem do trigo no Brasil, de 1983 a 1985. In: REUNIĀO NACIONAL DE PESQUISA DE TRIGO, 14., Londrina, PR, 1986. 312 p. (EMBRAPA - CNPT, Documentos, 8)

FELÍCIO, J.C; BARROS, B.C.; CAMARGO, C.E.O. \& BAR, W.H. Maracaí (IAC 17) e Xavantes (IAC 18): cultivares de trigo para o Estado de Sāo Paulo. Bragantia, Campinas, 42(1): 15-25, 1983.

; CAMARGO, C.E.O.; BARROS, B.C. \& VITTI, P. Iguaçu (IAC 21) e Araguaia (IAC 22): cultivares de trigo de sequeiro para o Estado de São Paulo. Bragantia, Campinas, 44(1): 115-128, 1985.

GOMES, F.P. Curso de estatística experimental. Piracicaba, Escola Superior de Agricultura "Luiz de Queiroz", 1963. 384p.

HANSON, H.; BORLAUG, N.E. \& ANDERSON, R.G. Trigo en el Tercer Mundo. México, Centro Internacional de Mejoramiento de Maiz y Trigo, 1982. $166 \mathrm{p}$.

OSÓRIO, E.A. Variedades e melhoramento. In: FUNDAÇAO CARGILL. Trigo no Brasil. Campinas, 1982. v.1,p.147-197.

PRIOLI, A.J. Análise genética da tolerância à toxidez do alumínio em milho (Zea mays L.). Campinas, UNICAMP, Instituto de Biologia, 1987. 182p. Tese (Doutoramento)

SCHRAM, W.; FULCO, W.S.; SOARES, M.H.G. \& ALMEIDA, A.W.P. Resistência de cultivares de trigo em experimentação ou cultivo no Rio Grande do Sul, às principais doenças fúngicas. Agronomia Sulriograndense, Porto Alegre, 10:31-39, 1974.

SILVA, E.M. da; LUCHIARI JUNIOR, A.; GUERRA, A.F. \& GOMIDE, R.L. Recomendação sobre o manejo de irrigação em trigo para a região dos cerrados. In: REUNIĀO DA COMISSĀO NORTE-BRASILEIRA DE PESQUISA DE TRIGO, 10., Campinas, 1984. Brasilia, EMBRAPA-CPAC, 1984, $60 \mathrm{p}$.

VITTI, P.; LEITÃO, R.F.F.; PIZZINATO, A. \& PENTEADO, R.L.B. Preparo de uma farinha de milho integral e desengordurada e seu uso em produtos de panificaçăo. Boletim do ITAL, Campinas, 17(4):451-467, 1980.

; MOREIRA, R.T. \& BAR, W.H. Estudo tecnológico do cultivar de trigo nacional IAC-18. Boletim do ITAL, Campirias, 19(2):183-94, 1982. 